\title{
White Matter Hyperintensities Potentiate Hippocampal Volume Reduction in Non-Demented Older Individuals with Abnormal Amyloid-beta
}

Citation for published version (APA):

Freeze, W. M., Jacobs, H. I. L., Gronenschild, E. H., Jansen, J. F. A., Burgmans, S., Aalten, P., Clerx, L., Vos, S. J., van Buchem, M. A., Barkhof, F., van der Flier, W. M., Verbeek, M. M., Rikkert, M. O., Backes, W. H., Verhey, F. R., \& LeARN Project (2017). White Matter Hyperintensities Potentiate Hippocampal Volume Reduction in Non-Demented Older Individuals with Abnormal Amyloid-beta. Journal of Alzheimer's Disease, 55(1), 333-342. https://doi.org/10.3233/JAD-160474

Document status and date:

Published: 01/11/2017

DOI:

10.3233/JAD-160474

Document Version:

Publisher's PDF, also known as Version of record

Document license:

Taverne

Please check the document version of this publication:

- A submitted manuscript is the version of the article upon submission and before peer-review. There can be important differences between the submitted version and the official published version of record.

People interested in the research are advised to contact the author for the final version of the publication, or visit the DOI to the publisher's website.

- The final author version and the galley proof are versions of the publication after peer review.

- The final published version features the final layout of the paper including the volume, issue and page numbers.

Link to publication

\footnotetext{
General rights rights.

- You may freely distribute the URL identifying the publication in the public portal. please follow below link for the End User Agreement:

www.umlib.nl/taverne-license

Take down policy

If you believe that this document breaches copyright please contact us at:

repository@maastrichtuniversity.nl

providing details and we will investigate your claim.
}

Copyright and moral rights for the publications made accessible in the public portal are retained by the authors and/or other copyright owners and it is a condition of accessing publications that users recognise and abide by the legal requirements associated with these

- Users may download and print one copy of any publication from the public portal for the purpose of private study or research.

- You may not further distribute the material or use it for any profit-making activity or commercial gain

If the publication is distributed under the terms of Article $25 \mathrm{fa}$ of the Dutch Copyright Act, indicated by the "Taverne" license above, 


\title{
White Matter Hyperintensities Potentiate Hippocampal Volume Reduction in Non-Demented Older Individuals with Abnormal Amyloid- $\beta$
}

\author{
Whitney M. Freeze ${ }^{a}, b, *$, Heidi I. L. Jacobs ${ }^{a}$, Ed H. Gronenschild ${ }^{a}$, Jacobus F. A. Jansen ${ }^{\text {b }}$, \\ Saartje Burgmans ${ }^{\mathrm{a}}$, Pauline Aalten ${ }^{\mathrm{a}}$, Lies Clerx ${ }^{\mathrm{a}}$, Stephanie J. Vos ${ }^{\mathrm{a}}$, Mark A. van Buchem ${ }^{\mathrm{c}}$, \\ Frederik Barkhof ${ }^{\mathrm{d}, \mathrm{e}}$, Wiesje M. van der Flier ${ }^{\mathrm{f}}$, Marcel M. Verbeek ${ }^{\mathrm{g}}$, Marcel Olde Rikkert ${ }^{\mathrm{h}}$, \\ Walter H. Backes ${ }^{\mathrm{b}}$ and Frans R. Verhey ${ }^{\mathrm{a}}$, on behalf of the LeARN project \\ ${ }^{a}$ Department of Psychiatry and Neuropsychology, Maastricht University, School for Mental Health and \\ Neuroscience, Alzheimer Center Limburg, Maastricht, The Netherlands \\ ${ }^{\mathrm{b}}$ Department of Radiology \& Nuclear Medicine, Maastricht University Medical Center, \\ School for Mental Health and Neuroscience, Maastricht, The Netherlands \\ ${ }^{\mathrm{c}}$ Department of Radiology, Leiden University Medical Center, Leiden, The Netherlands \\ ${ }^{\mathrm{d}}$ Department of Radiology \& Nuclear Medicine, VU University Medical Center, Amsterdam, The Netherlands \\ ${ }^{\mathrm{e}}$ Institutes of Neurology and Healthcare Engineering, University College Lodon, London, UK \\ ${ }^{\mathrm{f}}$ Department of Neurology, VU University Medical Center, Amsterdam, The Netherlands \\ ${ }^{\mathrm{g}}$ Departments of Neurology and Laboratory Medicine, Radboud University Medical Center Nijmegen, Donders \\ Institute for Brain, Cognition and Behaviour, and Radboud Alzheimer Center, Nijmegen, The Netherlands \\ ${ }^{\mathrm{h}}$ Department of Geriatric Medicine, Radboud University Medical Center Nijmegen, Donders Institute for Brain, \\ Cognition and Behaviour, and Radboud UMC, Alzheimer Center, Nijmegen, The Netherlands
}

Handling Associate Editor: Joel Ramirez

Accepted 10 August 2016

\begin{abstract}
Cerebral small vessel disease (cSVD) and amyloid- $\beta$ (Aß) deposition often co-exist in (prodromal) dementia, and both types of pathology have been associated with neurodegeneration. We examined whether CSVD and A $\beta$ have independent or interactive effects on hippocampal volume (HV) in a memory clinic population. We included 87 individuals with clinical diagnoses of Alzheimer's disease (AD) $(n=24)$, mild cognitive impairment (MCI) $(n=26)$, and subjective cognitive complaints (SCC) $(n=37)$. cSVD magnetic resonance imaging markers included white matter hyperintensity $(\mathrm{WMH})$ volume, lacunar infarct presence, and microbleed presence. $\mathrm{A} \beta$ pathology was assessed as cerebrospinal fluid-derived $\mathrm{A} \beta_{1-42}$ levels and dichotomized into normal or abnormal, and HV was determined by manual volumetric measurements. A linear hierarchical regression approach was applied for the detection of additive or interaction effects between cSVD and $\mathrm{A} \beta$ on HV in the total participant group $(n=87)$ and in the non-demented group (including SCC and MCI individuals only, $n=63$ ). The results revealed that abnormal $A \beta$ and lacunar infarct presence were independently associated with lower $\mathrm{HV}$ in the non-demented individuals. Interestingly, $\mathrm{A} \beta$ and $\mathrm{WMH}$ pathology interacted in the non-demented individuals, such that
\end{abstract}

${ }^{*}$ Correspondence to: Whitney M. Freeze, Department of Psychiatry and Neuropsychology, School for Mental Health and Neuroscience, Maastricht University, P.O. Box 616, 6200MD
Maastricht, The Netherlands. Tel.: +31 4338841 13; Fax: +31 4338840 92; E-mail: w.freeze@ maastrichtuniversity.nl. 
WMH had a negative effect on HV in individuals with abnormal CSF A $\beta_{42}$ levels, but not in individuals with normal CSF $\mathrm{A} \beta_{42}$ levels. These associations were not present when individuals with AD were included in the analyses. Our observations suggest that relatively early on in the disease process older individuals with abnormal A $\beta$ levels are at an increased risk of accelerated disease progression when concomitant cSVD is present.

Keywords: Amyloid-beta, cerebral small vessel disease, dementia, neurodegeneration

\section{INTRODUCTION}

Alzheimer's disease (AD) and vascular dementia $(\mathrm{VaD})$, the two most prevalent subtypes of dementia, are both characterized by progressive cognitive decline and neurodegeneration. Important pathophysiological processes underlying $\mathrm{AD}$ and $\mathrm{VaD}$ are cerebral amyloid-beta $(A \beta)$ protein deposition and cerebral small vessel disease (cSVD) [1, 2]. Even though both types of dementia are often considered as separate entities, they share many risk factors and $\mathrm{A} \beta$ and cSVD pathology frequently co-occur [3-6]. These observations suggest that the differentiation between $\mathrm{AD}$ and $\mathrm{VaD}$ can be difficult, and that the pure forms may rather represent two extremes of a pathologic continuum [7]. Moreover, recent studies report positive associations between cerebral $A \beta$ deposition and CSVD [8-12], and the presence of mixed $A \beta$ and $c S V D$ pathology has been shown to increase the risk of developing dementia [13]. These findings indicate that the underlying pathophysiological processes may be interdependent.

Hippocampal volume (HV) reduction is an important neurodegenerative marker for disease progression in dementia [14]. Hippocampal atrophy has been independently associated with both $A \beta$ pathology and cSVD in (prodromal) dementia [15, 16]. Interestingly, a recent animal study has pointed out that comorbid cerebrovascular damage and abnormal cerebral $A \beta$ levels may interact in causing hippocampal cell degeneration [17]. As such, presence of both elevated $A \beta$ and cerebrovascular pathology may predispose individuals to being more vulnerable to neurodegeneration compared to individuals with only a single type of pathology. To date, it remains unclear whether $A \beta$ deposition and cSVD interact in their detrimental effects on $\mathrm{HV}$ in individuals across the spectrum of dementia.

The aim of this study was to assess whether $A \beta$ and cSVD pathologies interact in their effects on HV. We investigated cerebrospinal fluid $A \beta_{42}$ levels as well as markers of cSVD pathology (white matter hyperintensities, lacunar infarcts, and microbleeds) and HV in a representative sample of aging memory clinic patients without large stroke. We hypothesized that
$\mathrm{A} \beta$ and cSVD pathologies interacted on HV, such that the negative effect of either type of pathology on $\mathrm{HV}$ would be larger in the presence of the other type of pathology. We expected that these interactions would be present during the early stages of the disease, when dynamic and most pronounced changes in $\mathrm{A} \beta$ accumulation occur before reaching a plateau [2]. Post-hoc, we examined whether there was an interaction on cognition, a topic that is still debated in the current literature [18-21]. Our results are important for the understanding of the cascade of pathological events in $\mathrm{AD}$.

\section{MATERIALS AND METHODS}

\section{Participants}

Participants were recruited via three academic memory clinics (Maastricht University Medical Center, Radboud University Medical Center, and VU University Medical Center) enrolled in the Dutch multi-center LeARN project. The process of recruitment and diagnostic classification has been described in detail elsewhere [22]. In short, patients with subjective and/or objective memory complaints who were suspected of having a primary neurodegenerative disease were included. The present study selected all participants with available cross-sectional data on magnetic resonance imaging (MRI), lumbar puncture, and neuropsychological assessment. Individuals with macrovascular abnormalities including large cerebral infarction (diameter $>15 \mathrm{~mm}$ ) or hemorrhage (diameter $>10 \mathrm{~mm}$ ) were excluded $(n=1)$. This resulted in a selection of 87 memory clinic patients, among which 37 individuals were diagnosed as having subjective cognitive complaints (SCC), 26 as having mild cognitive impairment (MCI), and 24 as having possible or probable AD. Diagnoses were made by experienced physicians based on core clinical criteria for MCI [23] and AD [24]. Criteria for SCC diagnosis included presence of subjective cognitive complaints, but absence of objective cognitive impairment in any of the cognitive domains, and absence of dementia. For all participants, educational 
level and medical history were recorded. Hypertension was defined as current use of antihypertensive medication. Diabetes was defined as known history of diabetes type 1 or 2 and cardiovascular disease as known history of myocardial infarction, angina pectoris, carotid stenosis, dotter/stent placement, and/or coronary bypass operation. The study was carried out in accordance with the rules and regulations of institutional research and ethics committees and written informed consent was obtained from all participants prior to participation [22].

\section{MRI data acquisition and processing}

At each medical center, MRI data were acquired on a 3.0 Tesla scanner. The scan protocol included a T1-weighted gradient-echo sequence, a fluid attenuated inversion recovery (FLAIR) sequence, as well as T2-weighted and susceptibility weighted imaging (SWI) sequences. The complete details of the acquisition and scan parameters per center can be found in the supplementary material (Supplementary Table 1). cSVD imaging markers were scored by expert raters who were trained to reach excellent intra-rater agreement compared to a gold standard (weighted kappa $\geq 0.85$ ), unless otherwise specified. Raters were always blinded for clinical data when scoring neuroimaging cSVD markers and structural changes.

\section{White matter hyperintensities (WMH)}

WMH volumes were quantified using a semiautomated method (in-house developed software package GIANT) [25]. For each medical center, an algorithm to classify WMH was trained separately, including the following steps. First, the FLAIR and T2 scans were corrected for intensity nonuniformities [26], followed by a co-registration of the T2 scans with the corresponding FLAIR scans using FLIRT from the FMRIB's Software Library (FSL) version 5.0.4 (http://www.fmrib.ox.ac.uk/fsl). Next, the signal intensities of the FLAIR and T2 scans were normalized [27]. Then we selected five scans with a substantial amount of WMH. The axial FLAIR and T2-weighted images were displayed side by side allowing visual inspection and easy identification of WMH while they were traced manually. From these manual tracings, parameters were derived for automated classification of WMH. Finally, the actual segmentation was performed semiautomatically by clicking on each identified WMH region in each slice of the simultaneously displayed axial FLAIR and T2-weighted images, providing a seed point to initiate a region growing algorithm. Manual corrections were performed where necessary by a single rater (W.M.F.). Excellent inter- and intra-rater variability were computed for a subset $(n=9)$ of scans that were also semi-automatically segmented by a second rater (S.B.) (intra class correlation both $>0.98$ ). Total WMH load was measured in $\mathrm{cm}^{3}$ and log-transformed to better approximate a normal distribution.

\section{Lacunar infarcts}

The number of lacunar infarcts was counted by characterizing lesions of minimal 3 to maximal $15 \mathrm{~mm}$ in diameter with a signal intensity identical to CSF on FLAIR and T2-weighted images, possibly surrounded by a hyperintense rim on FLAIR images. Lacunar infarct count was dichotomized as 0 (absent) versus 1 (present).

\section{Microbleeds}

Cerebral microbleeds (MBs) were defined as small, homogeneous, round foci of low signal intensity with associated blooming on SWI images of 2 to $10 \mathrm{~mm}$ in diameter [28]. Hypointensities at the site of the nucleus lentiformis, likely representing iron or calcium deposits, were excluded. MB scores were dichotomized as 0 (absent) versus 1 (present).

\section{Hippocampal volume}

Coronal T1-weighted images were reformatted in a plane perpendicular to the long axis of the (left) hippocampus, and HV was measured bilaterally by manual delineation as described previously $[29,30]$. In short, the most anterior slice measured was the slice where the hippocampal formation was first visible. The ventral border was formed by the white matter of the parahippocampal gyrus, while the dorsal border was formed by the amygdala on anterior slices and by CSF and choroid plexus on posterior slices. The HV included the dentate gyrus, cornu ammonis, subiculum, fimbria, and alveus. HV was computed by summing the delineated area of the region of interest on each slice and multiplying by the slice thickness. Delineation was done by expert raters with mean intrarater variability below 5\% and mean interrater variability below $8 \%$ (calculated from the ratio of the absolute difference in two measurements to the mean 
on a test set of scans, $n=10$ ). HV was measured in $\mathrm{cm}^{3}$ and expressed as the sum volume of the left and right hippocampus.

\section{Intracranial volume}

Intracranial volume (ICV) was derived from the T1 scans by using the SIENAX tool from FSL. ICV was measured in $\mathrm{cm}^{3}$.

\section{CSF analysis}

CSF was obtained by lumbar puncture between the L3/L4 or L4/L5 intervertebral space and stored at $-20^{\circ} \mathrm{C}$ in polypropylene tubes at each center. Samples of Maastricht and Nijmegen were transported to Amsterdam on dry ice for analysis. CSF $A \beta_{42}$ levels were quantified with commercially available INNOTEST sandwich enzyme-linked immunosorbent assays (Fujirebio, formerly Innogenetics, Ghent, Belgium) as previously described [31]. To classify individuals according to CSF $A \beta_{42}$ status (normal versus abnormal), routinely used validated cut-offs were applied, which could differentiate between subjects with SCC and AD-type dementia with $85 \%$ sensitivity (abnormal CSF A $\beta_{42} \leq 550 \mathrm{pg} / \mathrm{ml}$ ) [32].

\section{Cognition}

The Mini-Mental State Examination (MMSE) [33] was used to assess cognitive impairment and the Clinical Dementia Rating scale (CDR) was used to measure cognitive status. Neuropsychological testing for specific cognitive domains included quantitative tests to measure delayed memory recall (verbal 15 word learning test delayed word recall [34] [number of correctly reproduced words 20 minutes after the last learning trial]), language (Verbal Fluency Test [35] [number of correctly named animals within 1 minute]), and executive functioning (Stroop ColorWord Test [36] [interference score taken as outcome measure [37]]). Raw test scores were converted to $\mathrm{z}$-scores, adjusted for age, sex and education based on normative data [34, 35, 37].

\section{Statistical analysis}

All analyses were conducted using SPSS statistical software (version 22.0; IBM Corp., Armonk, NY). A threshold of $\alpha<0.05$ was used to determine statistical significance. Participant characteristics were described for each diagnostic group (SCC, MCI, AD).
One-way analyses of variance (ANOVA) were performed to assess group differences for continuous variables, and chi-squared tests or Fisher's exact tests (where applicable) to test for differences in proportions between groups for categorical variables.

\section{Interaction and additive effects of A $\beta$ status and $c S V D$ markers on $H V$}

We conducted linear hierarchical regression analyses to investigate our aims. First a baseline step 1 model was built, with covariates age, sex, ICV, center, and MMSE score (to correct for the degree of cognitive impairment) included. In step $2, A \beta_{42}$ status was added to the baseline model together with $\mathrm{WMH}$, lacunar infarcts, or MBs, and their interaction was added in the third step. Step 2 and 3 were performed for each cSVD marker separately. We applied these analyses to the total participant group, and to the non-demented group (including only SCC and MCI participants). We applied false discovery rate control to the $p$-values to correct for multiple comparisons of different predictor variables (three different cSVD markers as predictor of HV) [38] and checked whether possible outliers influenced the results.

\section{Post-hoc interaction and additive effects of $A \beta$ and cSVD markers on cognition}

We performed the same analyses with z-transformed cognitive measures of delayed memory recall, language, and executive functioning as dependent variables. Because $\mathrm{z}$-scores were already corrected for age, sex, and education, only MMSE score and center were included as covariates in step 1. Because MMSE score is associated with the cognitive outcome measures, and may as such explain a substantial amount of the variance, we also did the analyses with only center as a covariate in step 1 to see whether this changed the results. We applied false discovery rate control to the $p$-values to correct for multiple comparisons of the three different variables of interest [38].

\section{RESULTS}

Participant characteristics stratified by clinical status are summarized in Table 1. Individuals with AD were less often recruited via the MUMC and were more likely to have abnormal $A \beta_{42}$ levels compared with individuals with SCC. Individuals with AD or MCI were older, had smaller HVs, and had larger WMH volumes compared with participants 
with SCC. Individuals with $\mathrm{AD}$ had lower $\mathrm{A} \beta_{42}$ levels and less often lacunar infarction compared with all other individuals. CDR scores were higher in individuals with $\mathrm{AD}$ as compared with all other participants, whereas MMSE, delayed memory recall, language, and executive functioning scores were lower. Furthermore, CDR scores were higher, and MMSE and delayed memory recall scores were lower in participants with MCI as compared with participants with SCC.

\section{Interaction and additive effects of $A \beta$ and $c S V D$ markers on $H V$}

Table 2 shows the additive and interaction effects of CSF $A \beta_{42}$ status and different cSVD markers on HV. There were no independent or additive effects in the whole group analyses. In the nondemented group, abnormal CSF $\mathrm{A} \beta_{42}$ and lacunar infarct presence were both independently and additively associated with lower $\mathrm{HV}$ volume, but the effect

Table 1

Participant characteristics

\begin{tabular}{|c|c|c|c|}
\hline & SCC & MCI & $\mathrm{AD}$ \\
\hline & $(n=37)$ & $(n=26)$ & $(n=24)$ \\
\hline \multicolumn{4}{|l|}{ Demographics } \\
\hline Age, mean (SD), y & $63.7(9.3)$ & $69.2(8.4)^{\mathrm{a}}$ & $70.0(8.7)^{\mathrm{a}}$ \\
\hline Female sex, n (\%) & $11(30)$ & $7(27)$ & $9(38)$ \\
\hline Education, mean (SD), y & $12.0(3.8)$ & $11.1(3.1)$ & $10.7(3.2)$ \\
\hline MUMC, n (\%) & $20(54)$ & $11(42)$ & $5(21)^{\mathrm{a}}$ \\
\hline NUMC, n (\%) & $10(27)$ & $9(35)$ & $9(38)$ \\
\hline VUMC, n (\%) & $7(19)$ & $6(23)$ & $10(42)$ \\
\hline \multicolumn{4}{|l|}{ Vascular risk factors, $n(\%)$} \\
\hline Hypertension & $13(35)$ & $9(35)$ & $7(29)$ \\
\hline Diabetes mellitus & $1(3)$ & $4(15)$ & $4(17)$ \\
\hline Cardiovascular disease & $2(5)$ & $2(8)$ & $5(21)$ \\
\hline \multicolumn{4}{|l|}{ MRI characteristics } \\
\hline $\mathrm{WMH}$, mean $(\mathrm{SD}), \mathrm{cm}^{3}$ & $5.8(5.5)$ & $10.7(10.1)^{\mathrm{a}}$ & $10.1(9.2)^{\mathrm{a}}$ \\
\hline Lacunes present, n (\%) & $8(22)$ & $7(27)$ & $0(0)^{\mathrm{ab}}$ \\
\hline Microbleeds present, n (\%) & $10(27)$ & $7(27)$ & $6(25)$ \\
\hline $\mathrm{HV}$, mean (SD), $\mathrm{cm}^{3}$ & $6.7(0.8)$ & $5.8(1.0)^{\mathrm{a}}$ & $6.1(1.0)^{\mathrm{a}}$ \\
\hline $\mathrm{ICV}$, mean (SD), $\mathrm{cm}^{3}$ & $1951(171)$ & $1933(209)$ & $1901(135)$ \\
\hline \multicolumn{4}{|l|}{ CSF biomarker level } \\
\hline $\mathrm{A} \beta_{42}$, mean $(\mathrm{SD}), \mathrm{pg} / \mathrm{mL}$ & $776(249)$ & $737(284)$ & $540(173)^{\mathrm{ab}}$ \\
\hline Abnormal $\mathrm{A} \beta_{42}, \mathrm{n}(\%)$ & $8(22)$ & $10(38)$ & $13(54)^{\mathrm{a}}$ \\
\hline \multicolumn{4}{|l|}{ Cognition } \\
\hline MEM z-score, mean (SD) & $-0.5(1.1)$ & $-2.0(1.0)^{\mathrm{a}}$ & $-2.6(1.1)^{\mathrm{ab}}$ \\
\hline LA z-score, mean (SD) & $-0.59(0.70)$ & $-0.92(0.90)$ & $-1.50(0.72)^{\mathrm{ab}}$ \\
\hline EF z-score, mean (SD) & $-0.50(1.69)$ & $-0.10(1.35)$ & $-2.5(3.7)^{\mathrm{ab}}$ \\
\hline MMSE, mean (SD) & $28.2(1.4)$ & $27.2(2.2)^{\mathrm{a}}$ & $23.6(2.7)^{\mathrm{ab}}$ \\
\hline $\mathrm{CDR}$, mean $(\mathrm{SD})$ & $0.35(0.26)$ & $0.50(0.00)^{\mathrm{a}}$ & $0.84(0.24)^{\mathrm{ab}}$ \\
\hline
\end{tabular}

SCC, subjective cognitive complaints; MCI, mild cognitive impairment; AD, Alzheimer's disease; MUMC, Maastricht University Medical Center; NUMC, Nijmegen University Medical Center; VUMC, Vrije Universiteit Medical Center; WMH, white matter hyperintensities; HV, hippocampal volume; A $\beta$, amyloid-beta; MEM, delayed memory recall; LA, language; EF, executive functioning; MMSE, Mini-Mental State Examination; CDR, clinical dementia rating scale; $\mathrm{SD}$, standard deviation. ${ }^{\mathrm{a}} p<0.05$ versus $\mathrm{SCC} ;{ }^{\mathrm{b}} p<0.05$ versus MCI; Data were missing, LA z-score, $n=86$; EF z-score, $n=80 ; \mathrm{CDR}, n=81$.

Table 2

Additive and interactive effects of cSVD markers and CSF A $\beta_{42}$ on $\mathrm{HV}$

\begin{tabular}{|c|c|c|c|c|c|c|}
\hline & \multicolumn{3}{|c|}{ Whole group } & \multicolumn{3}{|c|}{ Non-demented individuals only } \\
\hline & \multicolumn{2}{|c|}{ Additive impact } & \multirow{2}{*}{$\frac{\text { Interaction }}{\text { cSVDxA } \beta_{42}}$} & \multicolumn{2}{|c|}{ Additive impact } & \multirow{2}{*}{$\frac{\text { Interaction }}{\mathrm{cSVDxA} \beta_{42}}$} \\
\hline & cSVD & $\mathrm{A} \beta_{42}$ & & cSVD & $\mathrm{A} \beta_{42}$ & \\
\hline WMH & -0.01 & -0.11 & -1.98 & -0.19 & $-0.31^{* *}$ & $-3.63^{*}$ \\
\hline Lacunes & -0.20 & -0.16 & 0.13 & $-0.30^{\S}$ & $-0.37^{*}$ & 0.25 \\
\hline MB & 0.11 & -0.12 & 0.08 & 0.16 & $-0.30^{*}$ & 0.20 \\
\hline
\end{tabular}

Values represent standardized beta coefficients. A $\beta$, amyloid-beta; WMH, white matter hyperintensities (log transformed); MB, microbleeds; $\mathrm{HV}$, hippocampal volume; cSVD, cerebral small vessel disease. ${ }^{\S} p=0.054 ;{ }^{*} p<0.05 ;{ }^{* *} p<0.01$ (after correction for multiple comparisons). 


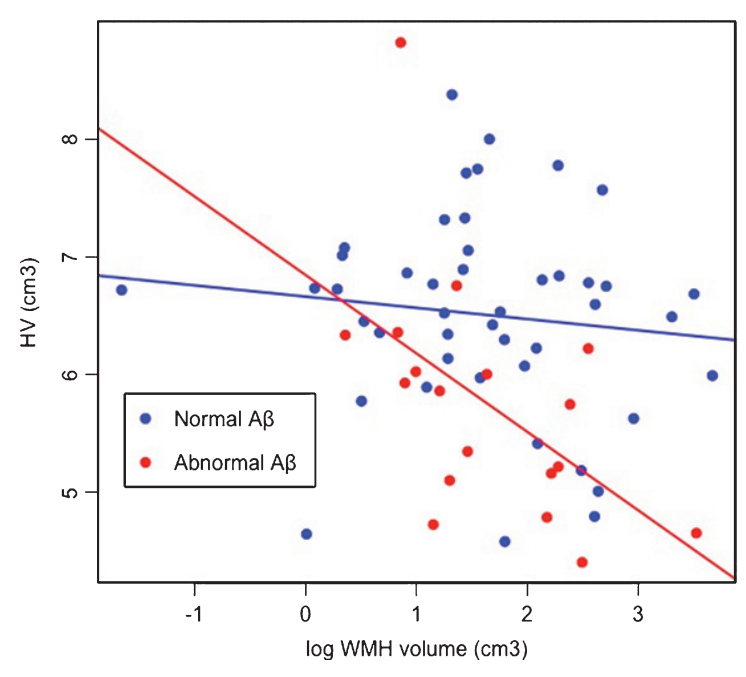

Fig. 1. The association between HV and WMH volume varies according to $A \beta_{42}$ status (dichotomized). Higher WMH volumes are associated with lower $\mathrm{HV}$ in individuals with abnormally low $\mathrm{CSFA}_{42}$ levels $(n=18 ; r=-0.53, p<0.05)$, but not in individuals with normal CSFA $\beta_{42}$ levels $(n=45 ; r=-0.12$, n.s.). A $\beta$, amyloid-beta; HV, hippocampal volume; $\mathrm{WMH}$, white matter hyperintensities; n.s., not significant. Unadjusted Pearson's correlations are reported.

of lacunar infarct presence remained only marginally significant after correction for multiple comparisons (i.e., $p=0.054$ ). Moreover, an interaction effect was present between CSF $A \beta_{42}$ and $\mathrm{WMH}$ volume in the non-demented group, such that larger WMH volumes were associated with lower HV volumes in individuals with abnormal CSF $A \beta_{42}$, but not in individuals with normal CSF $A \beta_{42}$ (Fig. 1). No interactions were found in the whole group analyses. Because exclusion of influential data points did not change the results, we used all data points in our analyses.

\section{Interaction and additive effects of $A \beta$ and $c S V D$ markers on cognition}

In the whole group and in the non-demented group, WMH volume was negatively associated with delayed memory recall performance (Supplementary Table 2). No other independent effects of cSVD markers or $A \beta_{42}$ were observed. There were no interaction effects between CSF $A \beta_{42}$ and the cSVD imaging markers on any cognitive measure in the whole group or in the non-demented group (Supplementary Table 2A-C). No changes occurred in the results when MMSE score was excluded from the model as a covariate.

\section{DISCUSSION}

The main objective of this study was to assess whether $A \beta$ and cSVD interact on HV in older individuals ranging from cognitively normal to demented. Our results indicated that abnormal CSF $\mathrm{A} \beta_{42}$ levels were independently associated with smaller HV in non-demented older individuals. In addition, cSVD burden in the form of lacunar infarct presence was associated with $\mathrm{HV}$ in this group (this effect remained marginally significant after correction for multiple comparisons). Although independent effects of WMH volume or MB presence on $\mathrm{HV}$ were absent in all analyses, the results did reveal an interaction effect between $A \beta_{42}$ pathology and $\mathrm{WMH}$ volume in the non-demented group. Interestingly, WMH had a negative relationship with $\mathrm{HV}$ in individuals with abnormal $A \beta_{42}$ levels, but such associations were absent in individuals with normal $A \beta_{42}$ levels. This interaction effect disappeared when individuals with dementia were included in the analyses. Importantly, these findings extend the current literature by showing that especially in the early stages of the disease process, individuals with $\mathrm{A} \beta$ pathology may be at increased risk for accelerated disease progression in the presence of comorbid cSVD pathology.

Our results are in line with recent work showing that the effects of cerebrovascular risk factors on cortical atrophy are influenced by the amount of A $\beta$ pathology [39]. The authors found that the negative effects of vascular risk on cortical thickness, especially in $\mathrm{AD}$ vulnerable regions, were increased when higher amounts of cerebral $A \beta$ deposition were present. This interaction effect was found in a similar population sample of non-demented individuals with normal and mildly impaired cognition. Our findings add new insights by showing that $A \beta$ pathology facilitates the impact of actual small vessel damage on neurodegeneration within the hippocampus, a crucial structure that is also highly vulnerable to $\mathrm{AD}$.

However, the existing literature remains inconclusive. Hohman et al. investigated the interplay between $\mathrm{A} \beta$ levels and cerebrovascular risk, and indicated a reversed interaction effect, such that cerebrovascular risk was strongest related to hippocampal atrophy in individuals without $A \beta$ pathology [40]. This reversed interaction effect might have been influenced by inclusion of clinical-stage dementia. In our analyses, inclusion of individuals with dementia made the interaction effect between cSVD and A $\beta$ disappear. It could be that at a later disease stage, $A \beta$ 
pathology related processes take over and the role of vascular factors becomes smaller [41]. Another recent study found no interaction between $A \beta$ levels and cerebrovascular pathology in cognitively normal individuals with hippocampal atrophy as outcome measure [42]. Although this was a well-designed longitudinal study, it could be that such interactions are not detectable at the earliest stages preceding subjective or objective cognitive problems. Additional work in population-based samples is needed to clarify the dynamic interplay between vascular damage and $A \beta$ from normal aging to dementia.

It remains unknown whether vascular and $A \beta$ pathology directly influence each other in their rates of pathologic progression, or whether these are simply distinct processes occurring in parallel. In case of the first scenario, cSVD pathology may lead to reduced parenchymal $A \beta$ clearance or increased deposition at the level of the neurovascular unit, while $A \beta$ accumulation in and around the cerebral vessels may in turn lead to small vessel damage. Such interactions have been reported in hypertensive rats [12]. These possible mechanisms need further exploration since they might have important implications for the diagnostic classification of $\mathrm{AD}$ and $\mathrm{VaD}$, suggesting that a continuous approach might be more appropriate than separate classification into $\mathrm{AD}$ and $\mathrm{VaD}$. In case of the independent processes scenario, it can be hypothesized that $\mathrm{A} \beta$ related processes reduce compensatory brain reserve [43, 44] and lower the threshold for (further) neurodegeneration due to cerebrovascular damage. Importantly, the interaction effect between $A \beta$ and $W M H$ found in the present study demonstrates that WMH pathology impacts hippocampal neurodegeneration only when abnormal $A \beta$ levels are already present. This suggests that individuals with both types of pathology are at increased risk of accelerated disease progression, which is in line with earlier findings that individuals with cerebrovascular damage are at increased risk of developing $\mathrm{AD}[13,45,46]$.

The fact that $A \beta$ pathology was independently associated with smaller HV in the non-demented sample is in accordance with previous studies consistently showing negative associations between cerebral $\mathrm{A} \beta$ deposition and $\mathrm{HV}$ at early disease stages $[47,48]$. Besides $A \beta$ pathology, lacunar infarct presence was independently and negatively associated with $\mathrm{HV}$, although this effect became marginally significant after adjusting for multiple comparisons. This finding suggests that hippocampal neurodegeneration may also be independently driven by vascular factors [16]. This effect was absent in the whole group analyses because none of the AD individuals displayed signs of lacunar infarction. We did not find any associations between $\mathrm{HV}$ and cerebral MBs or WMH volume. Although MBs have previously been associated with HV reduction [49], our sample included only a limited number (around 25\%) of participants that displayed these lesions. As such, our analyses may lack statistical power and sensitivity to detect associations between MBs and HV.

Post-hoc, we examined a possible interplay between $A \beta$ and cSVD on cognition. In line with previous studies, we found no interaction effects between $\mathrm{A} \beta$ and cSVD on various cognitive domains [19, $50,51]$. Although emerging evidence suggests that dementia is more likely to occur when vascular and $\mathrm{A} \beta$ pathology coexist $[13,45]$, it may be the case that the effects on cognition are mediated by neurodegenerative factors. For example, previous work indicated that the association between $\mathrm{A} \beta$ and cognitive decline is mediated by gray matter atrophy and glucose metabolism [52]. Others found that brain atrophy interacts with cSVD in affecting cognitive decline [53]. Thus, when not taking other factors into account, $A \beta$ and cSVD pathology may have independent or additive effects on cognition. Recent work supports the additive effect hypothesis by showing that cognitively normal individuals with both cerebrovascular and amyloid pathology displayed faster cognitive decline that seemed additive compared to the rate in individuals with only one type of pathology [21]. However, a recent study in individuals with subcortical vascular dementia reported interactions between cSVD and A $\beta$ pathology on longitudinal cognitive outcomes [20]. As such, the subtle interactive effects of cSVD and A $\beta$ may only become apparent at advanced disease stage and may only be detectable when cognition is measured longitudinally. Further studies are needed to clarify this matter.

Our results showed a relationship between WMH volume and delayed memory recall in the whole sample and in the non-demented individuals, which confirms the well-established association between cerebrovascular injury and cognition [21]. However, no associations between cognition and the other cSVD imaging markers were found. Although the prevalence of these markers was relatively high in the nondemented group $(\sim 25 \%)$, the sample size may have been too small to reveal any associations. While the association of $\mathrm{A} \beta$ pathology with cognition is less pronounced $[54,55]$, previous studies do indicate subtle independent associations with cognitive 
performance $[18,19]$. It is therefore important not to overlook the possible effects of both $A \beta$ and cerebrovascular disease when studying cognition in dementia. However, the effects of neurodegeneration, glucose metabolism, and other possible influencing factors should be taken into account.

Strengths of this study are the multi-center nature and representativeness of our study sample for general memory-clinic visiting individuals. Furthermore, the exclusion of large strokes enabled us to study the effects of mild cSVD in interaction with $A \beta$, although this may be a limitation to the generalizability of our results to populations with large vessel disease. The range in cognitive impairment allowed us to investigate our aims across the whole spectrum of dementia, from cognitively normal to mild dementia. Pitfalls of this study include its restricted sample size, the relatively low diversity of cSVD severity (The absence of lacunar infarcts in the AD group may form a potential sample bias in this study), and the cross-sectional nature of the data, which makes it impossible to make direct causal inferences. The multi-center nature may also be a confounding factor, because the scans are acquired on three different MR systems with different scan parameters. As such, the WMH volume calculation might have been influenced by center. We tried to correct for this by calculating separate algorithms for each center and by adding center as a covariate in the statistical models.

Taken together, the findings in this study suggest that $\mathrm{A} \beta$ pathology and cerebrovascular damage can both independently and synergistically facilitate hippocampal neurodegeneration in non-demented older individuals. Our results showed that cSVD in the form of lacunar infarcts was associated with smaller HVs in individuals with subjective to mild cognitive problems. Likewise, these individuals were more likely to have lower HV when abnormal cerebral A $\beta$ deposition was present. These associations were independent, meaning that their negative effects of $A \beta$ pathology and lacunar infarcts on $\mathrm{HV}$ were additive. In contrast, an interaction effect on $\mathrm{HV}$ was present between abnormal $\mathrm{A} \beta$ levels and $\mathrm{WMH}$ in the nondemented individuals. That is, WMH volume had no effect on HV in individuals with normal $A \beta$ levels, while HV reduction was (even further) amplified in individuals with abnormal cerebral $A \beta$ deposition when comorbid cerebrovascular disease in the form of WMH was present. We found no associations or interactions when individuals with AD were included in the analyses. Importantly, our results suggest that associations and interactions between $\mathrm{A} \beta$ and CSVD pathologies in relation to $\mathrm{HV}$ take place at the earlier stages of the disease process when cognitive impairment is only mild or not yet detectable. At this early stage, brain reserve may play a protective role, while during clinical disease stage other $A \beta$-related processes such as advanced neurodegeneration and/or tau pathology may have impacted this reserve. The observations in this study underline the importance of taking both cerebrovascular disease and $\mathrm{A} \beta$ deposition into account when studying cerebral atrophy in dementia. Vascular care in early memory clinic patients may form an important opportunity to slow down disease progression.

\section{ACKNOWLEDGMENTS}

This research was supported by the Center for Translational Molecular Medicine (http://www. ctmm.nl), project LeARN (grant 02N-101).

Authors' disclosures available online (http://j-alz. com/manuscript-disclosures/16-0474r1).

\section{SUPPLEMENTARY MATERIAL}

The supplementary material is available in the electronic version of this article: http://dx.doi. org/10.3233/JAD-160474.

\section{REFERENCES}

[1] Esiri MM, Wilcock GK, Morris JH (1997) Neuropathological assessment of the lesions of significance in vascular dementia. J Neurol Neurosurg Psychiatry 63, 749-753.

[2] Jack CR Jr, Knopman DS, Jagust WJ, Petersen RC, Weiner MW, Aisen PS, Shaw LM, Vemuri P, Wiste HJ, Weigand SD, Lesnick TG, Pankratz VS, Donohue MC, Trojanowski JQ (2013) Tracking pathophysiological processes in Alzheimer's disease: An updated hypothetical model of dynamic biomarkers. Lancet Neurol 12, 207-216.

[3] Attems J, Jellinger KA (2014) The overlap between vascular disease and Alzheimer's disease-lessons from pathology. BMC Med 12, 206.

[4] Carotenuto A, Rea R, Colucci L, Ziello AR, Molino I, Carpi S, Traini E, Amenta F, Fasanaro AM (2012) Late and early onset dementia: What is the role of vascular factors? A retrospective study. J Neurol Sci 322, 170-175.

[5] Jellinger KA (2007) The enigma of mixed dementia. Alzheimers Dement 3, 40-53.

[6] Kalaria RN, Akinyemi R, Ihara M (2012) Does vascular pathology contribute to Alzheimer changes? J Neurol Sci 322, 141-147.

[7] de la Torre JC (2004) Is Alzheimer's disease a neurodegenerative or a vascular disorder? Data, dogma, and dialectics. Lancet Neurol 3, 184-190.

[8] Grimmer T, Faust M, Auer F, Alexopoulos P, Forstl H, Henriksen G, Perneczky R, Sorg C, Yousefi BH, Drzezga A, 
Kurz A (2012) White matter hyperintensities predict amyloid increase in Alzheimer's disease. Neurobiol Aging 33, 2766-2773.

[9] Kaffashian S, Tzourio C, Soumare A, Dufouil C, Zhu Y, Crivello F, Maillard P, Schraen-Maschke S, Mazoyer B, Buee L, Debette S (2014) Plasma beta-amyloid and MRI markers of cerebral small vessel disease: Three-City Dijon study. Neurology 83, 2038-2045.

[10] Kester MI, Goos JD, Teunissen CE, Benedictus MR, Bouwman FH, Wattjes MP, Barkhof F, Scheltens P, van der Flier WM (2014) Associations between cerebral small-vessel disease and Alzheimer disease pathology as measured by cerebrospinal fluid biomarkers. JAMA Neurol 71, 855-862.

[11] Park JH, Seo SW, Kim C, Kim GH, Noh HJ, Kim ST, Kwak $\mathrm{KC}$, Yoon U, Lee JM, Lee JW, Shin JS, Kim CH, Noh Y, Cho H, Kim HJ, Yoon CW, Oh SJ, Kim JS, Choe YS, Lee KH, Lee JH, Ewers M, Weiner MW, Werring DJ, Na DL (2013) Pathogenesis of cerebral microbleeds: In vivo imaging of amyloid and subcortical ischemic small vessel disease in 226 individuals with cognitive impairment. Ann Neurol 73, 584-593.

[12] Schreiber S, Drukarch B, Garz C, Niklass S, Stanaszek L, Kropf S, Bueche C, Held F, Vielhaber S, Attems J, Reymann KG, Heinze HJ, Carare RO, Wilhelmus MM (2014) Interplay between age, cerebral small vessel disease, parenchymal amyloid-beta, and tau pathology: Longitudinal studies in hypertensive stroke-prone rats. J Alzheimers Dis 42(Suppl 3), S205-S215.

[13] Schneider JA, Arvanitakis Z, Bang W, Bennett DA (2007) Mixed brain pathologies account for most dementia cases in community-dwelling older persons. Neurology 69, 2197 2204.

[14] Jack CR Jr, Petersen RC, Xu YC, O'Brien PC, Smith GE, Ivnik RJ, Boeve BF, Waring SC, Tangalos EG, Kokmen E (1999) Prediction of AD with MRI-based hippocampal volume in mild cognitive impairment. Neurology 52, 13971403.

[15] Guzman VA, Carmichael OT, Schwarz C, Tosto G, Zimmerman ME, Brickman AM (2013) White matter hyperintensities and amyloid are independently associated with entorhinal cortex volume among individuals with mild cognitive impairment. Alzheimers Dement 9, S124-S131.

[16] Kim GH, Lee JH, Seo SW, Kim JH, Seong JK, Ye BS, Cho H, Noh Y, Kim HJ, Yoon CW, Oh SJ, Kim JS, Choe YS, Lee KH, Kim ST, Hwang JW, Jeong JH, Na DL (2015) Hippocampal volume and shape in pure subcortical vascular dementia. Neurobiol Aging 36, 485-491.

[17] Amtul Z, Nikolova S, Gao L, Keeley RJ, Bechberger JF, Fisher AL, Bartha R, Munoz DG, McDonald RJ, Naus CC, Wojtowicz JM, Hachinski V, Cechetto DF (2014) Comorbid Abeta toxicity and stroke: Hippocampal atrophy, pathology, and cognitive deficit. Neurobiol Aging 35, 1605-1614.

[18] Lee MJ, Seo SW, Na DL, Kim C, Park JH, Kim GH, Kim $\mathrm{CH}$, Noh Y, Cho H, Kim HJ, Yoon CW, Ye BS, Chin J, Jeon S, Lee JM, Choe YS, Lee KH, Kim JS, Kim ST, Lee JH, Ewers M, Werring DJ, Weiner MW (2014) Synergistic effects of ischemia and beta-amyloid burden on cognitive decline in patients with subcortical vascular mild cognitive impairment. JAMA Psychiatry 71, 412-422.

[19] Park JH, Seo SW, Kim C, Kim SH, Kim GH, Kim ST, Jeon S, Lee JM, Oh SJ, Kim JS, Choe YS, Lee KH, Shin JS, Kim CH, Noh Y, Cho H, Yoon CW, Kim HJ, Ye BS, Ewers M, Weiner MW, Lee JH, Werring DJ, Na DL (2014) Effects of cerebrovascular disease and amyloid beta burden on cognition in subjects with subcortical vascular cognitive impairment. Neurobiol Aging 35, 254-260.

[20] Ye BS, Seo SW, Kim JH, Kim GH, Cho H, Noh Y, Kim HJ, Yoon CW, Woo SY, Kim SH, Park HK, Kim ST, Choe YS, Lee KH, Kim JS, Oh SJ, Kim C, Weiner M, Lee JH, Na DL (2015) Effects of amyloid and vascular markers on cognitive decline in subcortical vascular dementia. Neurology $\mathbf{8 5}$, 1687-1693.

[21] Vemuri P, Lesnick TG, Przybelski SA, Knopman DS, Preboske GM, Kantarci K, Raman MR, Machulda MM, Mielke MM, Lowe VJ, Senjem ML, Gunter JL, Rocca WA, Roberts RO, Petersen RC, Jack CR Jr (2015) Vascular and amyloid pathologies are independent predictors of cognitive decline in normal elderly. Brain 138, 761-771.

[22] Handels RL, Aalten P, Wolfs CA, OldeRikkert M, Scheltens P, Visser PJ, Joore MA, Severens JL, Verhey FR (2012) Diagnostic and economic evaluation of new biomarkers for Alzheimer's disease: The research protocol of a prospective cohort study. BMC Neurol 12, 72

[23] Albert MS, DeKosky ST, Dickson D, Dubois B, Feldman HH, Fox NC, Gamst A, Holtzman DM, Jagust WJ, Petersen RC, Snyder PJ, Carrillo MC, Thies B, Phelps CH (2011) The diagnosis of mild cognitive impairment due to Alzheimer's disease: Recommendations from the National Institute on Aging-Alzheimer's Association workgroups on diagnostic guidelines for Alzheimer's disease. Alzheimers Dement 7, 270-279.

[24] McKhann G, Drachman D, Folstein M, Katzman R, Price D, Stadlan EM (1984) Clinical diagnosis of Alzheimer's disease: Report of the NINCDS-ADRDA Work Group under the auspices of Department of Health and Human Services Task Force on Alzheimer's Disease. Neurology 34, 939-944.

[25] Jacobs HI, Clerx L, Gronenschild EH, Aalten P, Verhey FR (2014) White matter hyperintensities are positively associated with cortical thickness in Alzheimer's disease. J Alzheimers Dis 39, 409-422.

[26] Sled JG, Zijdenbos AP, Evans AC (1998) A nonparametric method for automatic correction of intensity nonuniformity in MRI data. IEEE Trans Med Imaging 17, 87-97.

[27] Nyul LG, Udupa JK (1999) On standardizing the MR image intensity scale. Magn Reson Med 42, 1072-1081.

[28] Greenberg SM, Vernooij MW, Cordonnier C, Viswanathan A, Al-Shahi Salman R, Warach S, Launer LJ, Van Buchem MA, Breteler MM (2009) Cerebral microbleeds: A guide to detection and interpretation. Lancet Neurol 8, 165-174.

[29] van de Pol LA, van der Flier WM, Korf ES, Fox NC, Barkhof F, Scheltens P (2007) Baseline predictors of rates of hippocampal atrophy in mild cognitive impairment. Neurology 69, 1491-1497.

[30] Jack CR Jr (1994) MRI-based hippocampal volume measurements in epilepsy. Epilepsia 35(Suppl 6), S21-S29.

[31] Vos SJ, Visser PJ, Verhey F, Aalten P, Knol D, Ramakers I, Scheltens P, Rikkert MG, Verbeek MM, Teunissen CE (2014) Variability of CSF Alzheimer's disease biomarkers: Implications for clinical practice. PLoS One 9, e100784.

[32] Mulder C, Verwey NA, van der Flier WM, Bouwman FH, Kok A, van Elk EJ, Scheltens P, Blankenstein MA (2010) Amyloid-beta(1-42), total tau, and phosphorylated tau as cerebrospinal fluid biomarkers for the diagnosis of Alzheimer disease. Clin Chem 56, 248-253.

[33] Folstein MF, Folstein SE, McHugh PR (1975) Mini-mental state. A practical method for grading the cognitive state of patients for the clinician. J Psychiatr Res 12, 189-198.

[34] Van der Elst W, van Boxtel MP, van Breukelen GJ, Jolles J (2005) Rey's verbal learning test: Normative data for 1855 
healthy participants aged 24-81 years and the influence of age, sex, education, and mode of presentation. $J$ Int $\mathrm{Neu}$ ropsychol Soc 11, 290-302.

[35] Van der Elst W, Van Boxtel MP, Van Breukelen GJ, Jolles J (2006) Normative data for the Animal, Profession and Letter M Naming verbal fluency tests for Dutch speaking participants and the effects of age, education, and sex. J Int Neuropsychol Soc 12, 80-89.

[36] Stroop JR (1935) Studies of interference in serial verbal reactions. J Exp Psychol 18, 643-662.

[37] Van der Elst W, Van Boxtel MP, Van Breukelen GJ, Jolles J (2006) The Stroop color-word test: Influence of age, sex, and education; and normative data for a large sample across the adult age range. Assessment 13, 62-79.

[38] Benjamini Y, Hochberg Y (1995) Controlling the false discovery rate: A practical and powerful approach to multiple testing. J R Stat Soc Series B Methodol 57, 289-300.

[39] Villeneuve S, Reed BR, Madison CM, Wirth M, Marchant NL, Kriger S, Mack WJ, Sanossian N, DeCarli C, Chui HC, Weiner MW, Jagust WJ (2014) Vascular risk and Abeta interact to reduce cortical thickness in $\mathrm{AD}$ vulnerable brain regions. Neurology 83, 40-47.

[40] Hohman TJ, Samuels LR, Liu D, Gifford KA, Mukherjee S, Benson EM, Abel T, Ruberg FL, Jefferson AL (2015) Stroke risk interacts with Alzheimer's disease biomarkers on brain aging outcomes. Neurobiol Aging 36, 2501-2508.

[41] Chui HC, Zarow C, Mack WJ, Ellis WG, Zheng L, Jagust WJ, Mungas D, Reed BR, Kramer JH, Decarli CC, Weiner MW, Vinters HV (2006) Cognitive impact of subcortical vascular and Alzheimer's disease pathology. Ann Neurol 60, 677-687.

[42] Vemuri P, Knopman DS (2016) The role of cerebrovascular disease when there is concomitant Alzheimer disease. Biochim Biophys Acta 1862, 952-956.

[43] Mormino EC (2014) The relevance of beta-amyloid on markers of Alzheimer's disease in clinically normal individuals and factors that influence these associations. Neuropsychol Rev 24, 300-312.

[44] Huijbers W, Mormino EC, Schultz AP, Wigman S, Ward AM, Larvie M, Amariglio RE, Marshall GA, Rentz DM, Johnson KA, Sperling RA (2015) Amyloid-beta deposition in mild cognitive impairment is associated with increased hippocampal activity, atrophy and clinical progression. Brain 138, 1023-1035.

[45] van der Flier WM, Middelkoop HA, Weverling-Rijnsburger AW, Admiraal-Behloul F, Spilt A, Bollen EL, Westendorp RG, van Buchem MA (2004) Interaction of medial temporal lobe atrophy and white matter hyperintensities in AD. Neurology 62, 1862-1864.

[46] Tosto G, Zimmerman ME, Hamilton JL, Carmichael OT, Brickman AM (2015) The effect of white matter hyperintensities on neurodegeneration in mild cognitive impairment. Alzheimers Dement 11, 1510-1519.

[47] Chetelat G, Villemagne VL, Bourgeat P, Pike KE, Jones G, Ames D, Ellis KA, Szoeke C, Martins RN, O'Keefe GJ, Salvado O, Masters CL, Rowe CC (2010) Relationship between atrophy and beta-amyloid deposition in Alzheimer disease. Ann Neurol 67, 317-324.

[48] Mormino EC, Kluth JT, Madison CM, Rabinovici GD, Baker SL, Miller BL, Koeppe RA, Mathis CA, Weiner MW, Jagust WJ (2009) Episodic memory loss is related to hippocampal-mediated beta-amyloid deposition in elderly subjects. Brain 132, 1310-1323.

[49] Chowdhury MH, Nagai A, Bokura H, Nakamura E, Kobayashi S, Yamaguchi S (2011) Age-related changes in white matter lesions, hippocampal atrophy, and cerebral microbleeds in healthy subjects without major cerebrovascular risk factors. J Stroke Cerebrovasc Dis 20, 302-309.

[50] Marchant NL, Reed BR, DeCarli CS, Madison CM, Weiner MW, Chui HC, Jagust WJ (2012) Cerebrovascular disease, beta-amyloid, and cognition in aging. Neurobiol Aging 33, 1006. e1025-1036.

[51] Marchant NL, Reed BR, Sanossian N, Madison CM, Kriger S, Dhada R, Mack WJ, DeCarli C, Weiner MW, Mungas DM, Chui HC, Jagust WJ (2013) The aging brain and cognition: Contribution of vascular injury and abeta to mild cognitive dysfunction. JAMA Neurol 70, 488-495.

[52] Ewers M, Insel P, Jagust WJ, Shaw L, Trojanowski JQ, Aisen P, Petersen RC, Schuff N, Weiner MW (2012) CSF biomarker and PIB-PET-derived beta-amyloid signature predicts metabolic, gray matter, and cognitive changes in nondemented subjects. Cereb Cortex 22, 1993-2004.

[53] Jokinen H, Lipsanen J, Schmidt R, Fazekas F, Gouw AA, van der Flier WM, Barkhof F, Madureira S, Verdelho A, Ferro JM, Wallin A, Pantoni L, Inzitari D, Erkinjuntti T (2012) Brain atrophy accelerates cognitive decline in cerebral small vessel disease: The LADIS study. Neurology 78, 1785-1792.

[54] Aizenstein HJ, Nebes RD, Saxton JA, Price JC, Mathis CA, Tsopelas ND, Ziolko SK, James JA, Snitz BE, Houck PR, Bi W, Cohen AD, Lopresti BJ, DeKosky ST, Halligan EM, Klunk WE (2008) Frequent amyloid deposition without significant cognitive impairment among the elderly. Arch Neurol 65, 1509-1517.

[55] Villemagne VL, Pike KE, Chetelat G, Ellis KA, Mulligan RS, Bourgeat P, Ackermann U, Jones G, Szoeke C, Salvado O, Martins R, O'Keefe G, Mathis CA, Klunk WE, Ames D, Masters CL, Rowe CC (2011) Longitudinal assessment of Abeta and cognition in aging and Alzheimer disease. Ann Neurol 69, 181-192. 